except for a slight discoloration due to a sulphide film, were almost unaffected, but the zinc coating on the galvanized iron heating coils had completely disappeared, although this may have been due to electrolytes other than sulphides. Rubber was apparently unaffected.

Experiments were also continued on the final disposal of concentrated foam liquids, with particular reference to stripping by means of activated carbon. Aqueous solutions of 1,000 p.p.m. of sodium tetrapropylene benzene sulphonate were passed through a column of $1 \mathrm{in}$. diam. and $8 \mathrm{in}$. long, containing 100 gm. of activated carbon. The carbon was soaked in water before use, and care was taken to maintain the liquid level half an inch above the carbon column. During continuous flow the activated charcoal showed almost complete adsorption of the detergent present in the solution in the early part of the test; it was capable of extracting about 90 per cent of the detergent after it had adsorbed 27 per cent of its own weight of surface-active material and could still extract 50 per cent after adsorbing 38 per cent of its own weight. In a later experiment, a solution of 1,000 p.p.m. of sodium tetrapropylene benzene sulphonate in the final effiuent from an activated sludge plant was passed through a column containing $100 \mathrm{gm}$. of activated carbon. A gauze pad was used to intercept suspended solids before the liquid reached the activated carbon in order to avoid choking the interstices in the column. Although adsorption was good, there was evidence that the carbon failed more quickly than when aqueous solutions were used, probably because of adsorption of other constituents of the effluent.

As activated carbon is expensive, attention was given to the possibility of regenerating the material. Attempts to displace the surface-active materials with solvents had only a limited success, and acidification of the dried exhausted carbon, followed by extraction with trichlorethylene, resulted in the removal of only a small proportion of the synthetic detergent in the form of its sulphonic acid.

The most promising method of disposal of condensed foam liquids appeared to be by spraying the foam with surface-activated sludge and allowing the solid content of the material to settle. In the process, the detergent concentration of the supernatant liquor might be expected to be reduced from about $500-600$ to $30-40$ parts per million, which could easily be treated by admission to primary sedimentation tanks.

Continuing a long-term investigation into the incidence of air pollution, volumetric instruments again indicated a reduction of 7 per cent in the average concentration of smoke in the air of London during the year, and this progressive tendency for improvement has continued since the inception of the Clean Air Act at the beginning of 1957. The sulphur dioxide concentration, for the first time, showed a similar reduction. The improvement was mainly attributable to exceptionally good weather in December, in which the average smoke concentration was only half the usual figure. It is probable that mild weather at the end of the year resulted in reduced domestic coal consumption, and, if this is true, the improvement may not be permanent. It is of interest that during the unusually fine summer the degree of pollution, though naturally low, was very similar to that of the previous cold, wet summer.

A five-month investigation into conditions at Camden Depot was completed, showing that a house adjacent to the railway was subjected to concentrations of black smoke and sulphur dioxide which were on the average 102 and 43 per cent respectively higher than the general London-levels. With the wind in certain directions, the average concentrations rose to at least 200 and 100 per cent respectively above the same London-levels. The situation is expected to improve with the gradual replacement of steam by Diesel locomotives.

\title{
RESEARCH IN THE SOCIAL SCIENCES
}

$\mathrm{P}^{\mathrm{K}}$ IORITIES for research in the social sciences in industry have been indicated by A. B. Cherns, head of the Human Sciences Section, Department of Scientific and Industrial Research (Personnel Management, 42, No. 353 ; December 1960). In the field of ergonomics, for example, Cherns suggests that the man-machine relationship is a vital aspect of the study of man in industry. The social implications of the man-machine system are such as to justify more attention from social scientists perhaps as members of mixed ergonomic and sociological teams. Ergonomics is a field in which practical applications are easy to appreciate.

The development of adequate criteria of industrial relations should receive a high priority. Have the criteria also to develop indicators? Could the industrialist be advised what chart he should put on his wall to give him a guide to the industrial relations formulated in his plant? Until this be done, the claim to have extracted the full practical value from research cannot be substantiated. A wide comparative study would seem to be required.
The approach of Flanders and others, which aims at developing a study of industrial relations in all its aspects-economic, legal, psychological, sociological and historical-may woll provide the stimulation that is needed both to give point to and to encourage wide comparative studies.

Thero has been an uneasy tug-of-war between interpretations of workshop behaviour based on views of the man in the workshop as an economical and rational animal and those based on views of him as a nexus of social roles-the economic and the sociological points of view. More accurate and systematic observation is a high priority - but not of the extended, reporting type with platitudinous conclusions.

More analysis of the pressures on the individual in industry is required ; in particular, incentive payment systems, mothods and standards of inspection, the structure and organization of management, and delegation of responsibility.

The study of individual responses to pressures is as important as the study of the pressures themselves. 
The new enthusiasm for industrial sociology has tended to obscure the older studies of individual differences. It may now be time to look at these again in the light of better understanding of the social pressures involved.

Examination of status systems in industry is not new. Nevertheless, there is need to know more about the extent to which the use of the special knowledge and ability of the technician or technologist is hindered by the status systems in industry, particularly the caste system dividing management from technical grades. This is in need of overhaul based on sociological understanding.

The work of Simon and his associates in the United States has shown what can come from a rigorous analysis of some aspects of decision taking. There is a point in each organization at which there is someone who has the necessary authority to take a particular decision. Also located in this organization is someone who has the knowledge for the best decision to be taken. The problem is how to get these two points to coincide: How can effective authority coincide with effective knowledge ?
Industrial relations generally means relationship of management to labour. Equally important for the health of any concern is its management/management relations. These may not burst into active conflict, but latent conflict is continuous and may be dangerous. This conflict is neither altogether avoidable nor altogether bad; every time a functional organization is set up a conflict of interest is created. Each functional department tends to seek to maximize what, from the point of view of the organization as a whole, needs to be optimized. For example, a production department will naturally have maximum production as its goal; an inspection departmont will naturally tend to seek maximum quality or minimum errors. From the point of view of the concern as a whole, a compromise between these conflicting aims has to be achieved. Less obvious but equally profound conflicts of aim will occur between the personnel department and the department of the accountent or financial controller. The problem is not how to resolve this conflict but how best to use it and keep it within bounds.

T. H. Hawkins

\section{TRAINING ENGINEERING GRADUATES}

$\mathrm{T}$ HE graduate aiming at membership of one of the professional engineering institutions normally undergoes a period of practical training or apprenticeship following the completion of his undergraduate course.

Some three years ago the Institution of Electrical Engineers issued a report entitled "The Training of Graduates" in which the purposes of practical training for graduates were outlined and recommendations for the structure of training courses were made. This report, revised and modified, has now been re-issued*.

The general pattern of training recommended does not differ in its essential features from that described in the earlier report. Training should occupy two years and should comprise basic workshop training, general mechanical and electrical training and what is termed directed objective training. It is emphasized that each phase of the training course should be carefully plenned and supervised and that the graduate in his practical training should continue to experience something of the intellectual stimulus and of the urge to intensive individual effort which are inherent in academic studies.

- Institution of Electrical Engineers. The Training of Graduates : a Report of the Joint Committee on Practical Training in the Elec trical Engineering Industry. Pp. 34. (London : Institution of Electrical Engineers, 1960.) $2 s$.
Separate sections of the report deal with schemes of training conducted in a works making heavy electrical plant, a factory for light-current equipment and in an operating organization, such as an electricity supply undertaking or a telecommunication service.

While the majority of electrical engineers study, as undergraduates, electrical engineering, a substantial proportion read physics and a few mathematics. The special needs and interests of such graduates in physics and mathematics are met by a scheme of training based on the laboratory but providing for some direct contact with manufacture and development.

There is one important new feature in the recommendations. This is the recognition of training through experience in a staff appointment as an alternative to the traditional form of graduate apprenticeship. This envisages the graduate being engaged as a member of the staff of a professional engineer who will directly supervise his training. The training course will not then conform to any standard pattern, but will comprise the acquiring of experience on a series of projects. These will be so chosen as to provide in the aggregate a range of experience equivalent to that provided by the normal graduate apprenticeship. Great stress is laid on the personal responsibility accepted by the engineer who undertakes to provide this type of training.

\section{POLIOMYELITIS}

CINCE the last World Health Organization special$S$ ist Committee on Poliomyelitis met in 1957 not only have inactivated poliovirus vaccines come into widespread use but also live attenuated vaccines have been submitted to intensive study and, in some countries, have already been employed on a scale that could scarcely have been envisaged three years ago. These developments and the problems they raise are fully reviewed in the third report of the
Committee (Expert Committee on Poliomyelitis, Third Report. World Health Organization: Technical Report Series, 1960, No. 203 ; 53 pages. Price : 3s. 6d., 0.60 dollars, Sw. Fr. 2. Also available in Spanish and French).

In most countries where inactivated vaccines have been widely used the protection obtained has been of the order expected on the basis of controlled field trials. Manufacturing and testing problems appear to 